\title{
Study of Factors Affecting Tensile Strength of Grey Cast Iron
}

\author{
Abhijit Ramesh Patil ${ }^{1}$, P. N. Gore ${ }^{2}$ \\ ${ }^{1} P G$ student at DKTE's Textile and Engineering Institute, Ichalkaranji, India \\ ${ }^{2}$ Associate professor at DKTE's Textile and Engineering Institute, Ichalkaranji \\ Iabpkit@gmail.com \\ ${ }^{2}$ purushottamgore@yahoo.com
}

\begin{abstract}
Tensile strength of a material is the capacity of material to withstand tensile force without failure. Tensile strength is important mechanical property of material which gives direction to use it for proposed application safely. It is very important parameter considered in designing sound product. Grey cast iron carries properties like high compressive strength, castable, good machinability, good abrasion resistance, high thermal conductivity, resist to expand under high temperature. Tensile strength of grey cast depends mainly on carbon content, steel scrap \% used, inoculation, graphite morphology, cooling time. Present paper summarizes study of factors affecting tensile strength of grey cast iron. With the study of factors affecting the tensile strength of cast iron it is very helpful to achieve required tensile strength by controlling the factors affecting strength of the material. While studying and experimenting on the behavior of tensile strength, clear idea comes into the picture how the strength is affected.
\end{abstract}

Keywords: Grey cast iron, Tensile strength, Carbon content, Inoculation, Cooling time.

\section{Introduction:}

Tensile strength of a material is a mechanical property which states that how much tensile load a material can bear safely without failure. Tensile strength is very much important mechanical property while designing a sound product in industries such as Aerospace industry, Automobile industry, Medical industry, Construction industry etc. While designing a product great care is to be taken to choose suitable material which has required properties to perform its intended function safely and effectively without failure. So, the material used for defined function has to be required mechanical properties otherwise effect may be disastrous. It is needed to choose the material which beers better mechanical properties with factor of safety not to reach stresses exceeding the capacity of material. Tensile strength is an intensive property which means it is independent on amount but is dependent only on type of matter or material.

The material used for Internal combustion engine should capable to withstand at high working temperature, able to withstand vibration and corrosion resistance and has to be high strength mostly in diesel engine as compare to petrol engine. Compression ratio in diesel engine is normally higher (17:1) than petrol engine (10:1). The material suitable for internal combustion engine is grey cast iron. The tensile strength of grey cast iron is tested on Universal Tensile Testing Machine (UTM). The cast iron material used for internal combustion is casted in the form of bar and machined to standard dimension to check tensile strength on UTM. Tensile strength of material contributes very important role in the sense of performance and quality of product to carry out its intended work function. Tensile strength of material mainly depends on chemical composition, molecular structure, operating temperature, cooling condition, graphite morphology, charge material used. Intermolecular forces are generated in the material due molecular structure in the 
material. The molecules in the material are bounded by this intermolecular force therefore changes in molecular structure cause change in the strength of material. Operating temperature is important factor which may affect the change in tensile strength of material. As temperature of material is increased, up to some point tensile strength of material increases and beyond this point starts decreasing. The changes in molecular structure is caused by increase in temperature of material.

Mainly tensile strength of material depends on chemical composition in it. From the studies it is observed that pure iron has lower tensile strength and iron with alloys bears higher tensile strength. This is because of molecular structure in the material. The cooling condition of material after it is casted affects tensile strength of material. Cooling condition decides the morphological phase formation which greatly affects the strength of material.

\subsection{Literature Review:}

1. V. Fourlakidis, L. V. Diaconu, b and A. Dioszegi presented paper on 'Effects of Carbon Content on the Ultimate Tensile Strength in Grey Cast Iron'. In this research it is described that effect of carbon content of grey cast iron on the tensile strength. This research also shows the behavior of tensile strength against different cooling condition. This helps to study how the carbon content in the grey cast iron affects the tensile strength. From the study it comes to know how important is the carbon content and cooling condition of casted material.

2. Hiren V. Mandalia, Vijaykumar R. chavda presented paper on 'Effect of Chemical Composition on Total Carbon Equivalent in Grey Iron Casting'. In this research paper the constituents of cast iron that affects strength and hardness are studied with experiment. From the study it comes to know that the how tensile strength of grey cast iron changes with respect to carbon equivalent.

3. Peter Futas, Alena Pribulova Gabriel Fedorko and Vieroslav Molnar presented paper on 'Influence of Steel Scrap in the Charge on the Properties of Grey Cast Iron'. To produce grey cast iron different type of charge materials are used. From this research it shows that ratio of steel scrap used effects considerably on properties of grey cast iron. This paper shows the study of different charge material ratios that are used to produce grey cast iron and how it affects on mechanical properties of produces grey cast iron.

4. V. Fourlakidis, L. V. Diaconu, b and A. Dioszegi presented paper on 'Microstructure and tensile properties on grey cast iron'. In this paper it is described that ultimate tensile strength of grey cast iron closely depending on graphite flakes and morphological phases. The research also helps to know that parameters like inoculation, carbon content, microstructure and cooling condition of material while solidification affects the tensile strength of grey cast iron.

5. Prof.S.C.Borse, Y.E.Mangulkar presented paper on 'Review on Grey Cast Iron Inoculation'. This review paper gives description about behaviour of tensile strength with respect to inoculant added while pouring the liquid metal. This paper enlightens some inoculants used by researchers to achieve required properties of grey cast iron. This is helpful to carry out further experiment to study behavior of tensile strength of cast iron with respect to inoculant used.

\subsection{Objectives:}

To study the behavior of tensile strength of grey cast iron against the factors MS scrap \%, Carbon content in the melt, Pouring temperature, Cooling time, \% of inoculant, Base of inoculant. 


\subsection{Direction from Literature Review:}

Before starting the research study, literature studies helped to experiment direction to study the behavior of tensile strength of cast iron against factors affecting tensile strength. From the literature review it comes to know that the tensile strength of grey cast iron is affected by the usage of MS scrap \% in its melt. It has the base that MS scrap beers more tensile strength as compare to other raw materials used to prepare melt of grey cast iron. Therefore, as percentage of MS scrap increased, then tensile strength of grey cast iron goes on increasing as well provided that keeping chemical composition of melt same.

In the study of mechanical properties of SG iron, it comes to know that the tensile strength of SG iron material goes on increasing as inoculant is added in it. This study informs that the precipitation of graphite is increased rather than carbide precipitation by the addition of inoculant in the melt at the time of pouring. Addition of inoculant reduces the solubility of carbon in the solution at the time of solidification and graphite phase is formed which is soft and helps to improve tensile strength of grey cast iron. Carbide is the brittle material and reduces the tensile strength of grey cast iron.

While studying research paper regarding mechanical properties of grey cast iron it comes to know that the cooling condition of melt affects its mechanical properties as well. The cooling time, cooling environment also affects the mechanical properties of material at the time of solidification. Cooling environment in the chilling condition, sand cooling condition, insulation condition gives different results of mechanical properties of cast iron. This shows that cooling condition and cooling rate affects the mechanical properties of cast iron. This study shows that tensile strength and hardness goes on increasing for the condition of insulation, sand cooling and chilling condition respectively.

\section{Experimental Design:}

1) Tensile strength analysis against same MS \% and different carbon content. To study the behavior of tensile strength of grey cast iron against different $\%$ of carbon content in the melt keeping MS scrap \% same, test bars are poured as per following specifications. Melt is prepared with MS scrap \% of 15, 30, 40 and $50 \%$ and carbon content is varied from 3.20 to 3.35 and test bars are poured keeping other alloying elements unchanged.

Carbon content in the melt precipitates in the form of graphite and graphite is softer phase of material in the cast iron solution. Therefore, increase in the $\%$ of carbon content in the cast iron melt, makes material softer.

Table no. 1.1 Same MS Scrap \% but Different Carbon Content

\begin{tabular}{|c|c|c|c|}
\hline MS \% & Carbon & Tensile strength (Mpa) & Hardness (BHN) \\
\hline \multirow{3}{*}{$15 \%$} & 3.2 & 286 & 191 \\
\cline { 2 - 4 } & 3.25 & 267 & 185 \\
\cline { 2 - 4 } & 3.34 & 213 & 179 \\
\hline \multirow{3}{*}{$30 \%$} & 3.26 & 276 & 205 \\
\cline { 2 - 4 } & 3.3 & 272 & 204 \\
\cline { 2 - 4 } & 3.36 & 263 & 200 \\
\hline \multirow{3}{*}{$40 \%$} & 3.22 & 280 & 212 \\
\cline { 2 - 4 } & 3.25 & 281 & 206 \\
\cline { 2 - 4 } & 3.31 & 277 & 200 \\
\hline \multirow{3}{*}{$50 \%$} & 3.22 & 304 & 225 \\
\cline { 2 - 4 } & 3.25 & 286 & 217 \\
\cline { 2 - 4 } & 3.34 & 263 & \\
\hline
\end{tabular}




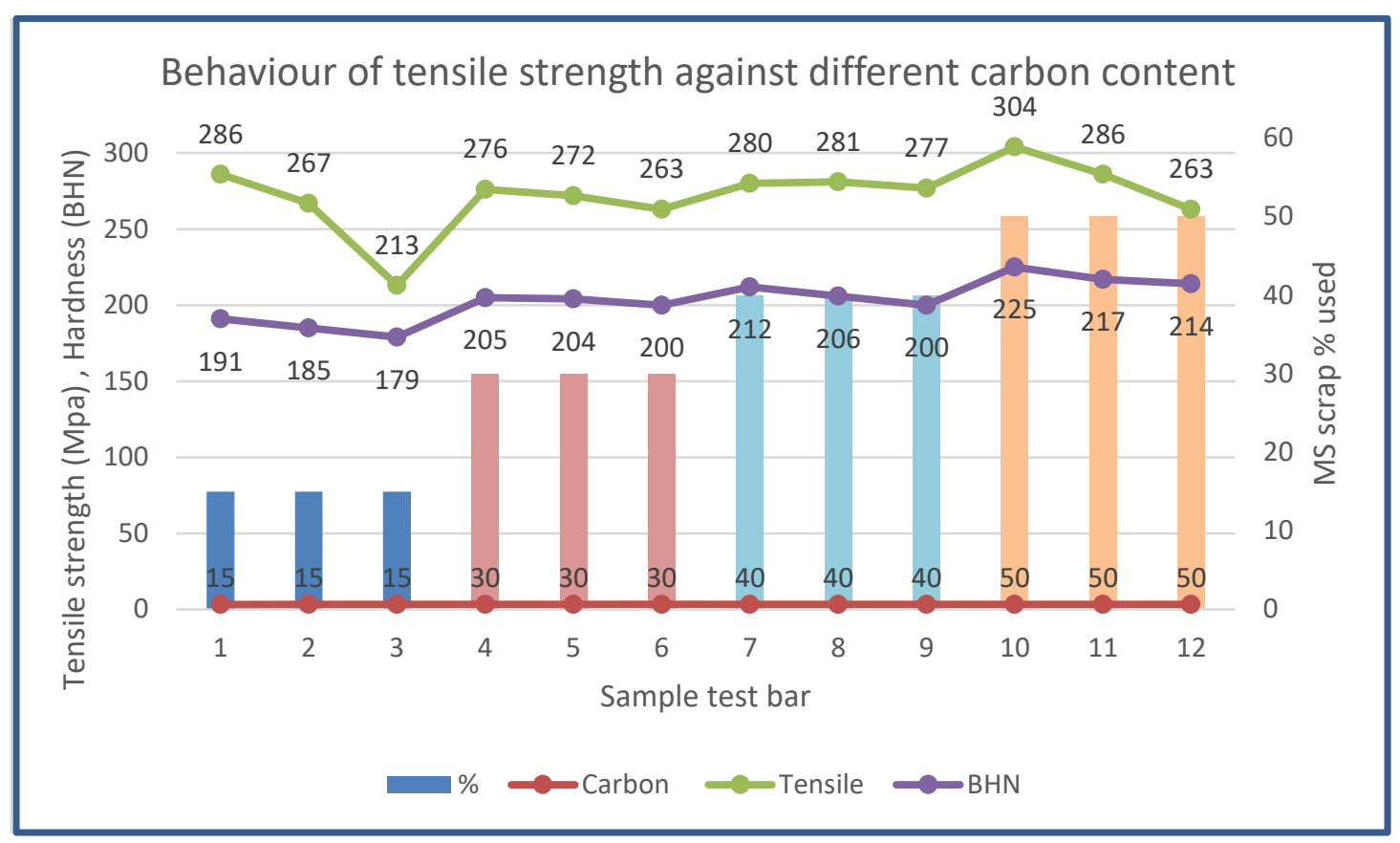

Figure 1.2 Same \% of MS Scrap but Different Carbon Content

2) Tensile strength analysis against same Carbon content and different MS \%.

To study the behavior of tensile strength of grey cast iron with respect to MS scrap \% used in the melt, keeping carbon content in the melt unchanged, test bars are poured as per following specifications. Melt is prepared with different MS scrap \% of 15, 30, 40 and $50 \%$ and carbon content of melt is kept same about 3.25 and test bars are poured keeping other alloying elements unchanged.

The tensile strength of steel is generally observed in the range from 400 to 550 Mpa. approximately and hardness is about 130 to 150 BHN. From this data of hardness of MS scrap, increase in \% of MS scrap, hardness of material should be lowered. But this is not happened because carbon content in the cast iron is

Total carbon $=[($ Free carbon $)+($ Combined carbon $)]$

Here by the increasing the MS scrap \% leads to form combined carbon rather than free carbon. Free carbon means graphite phase which is softer and combined carbon means $\mathrm{Fe}_{3} \mathrm{C}$ which is harder phase in the cast iron solution. That's why increase in \% of MS scrap, hardness of cast iron goes on increasing.

Table 2.1 Same Carbon content but different MS scrap \%

\begin{tabular}{|c|c|c|c|c|}
\hline Sr. & MS Scrap \% & Carbon & Tensile strength (Mpa) & Hardness (BHN) \\
\hline 1 & 15 & 3.25 & 267 & 185 \\
\hline 2 & 30 & 3.26 & 276 & 205 \\
\hline 3 & 40 & 3.25 & 281 & 206 \\
\hline 4 & 50 & 3.25 & 286 & 217 \\
\hline
\end{tabular}




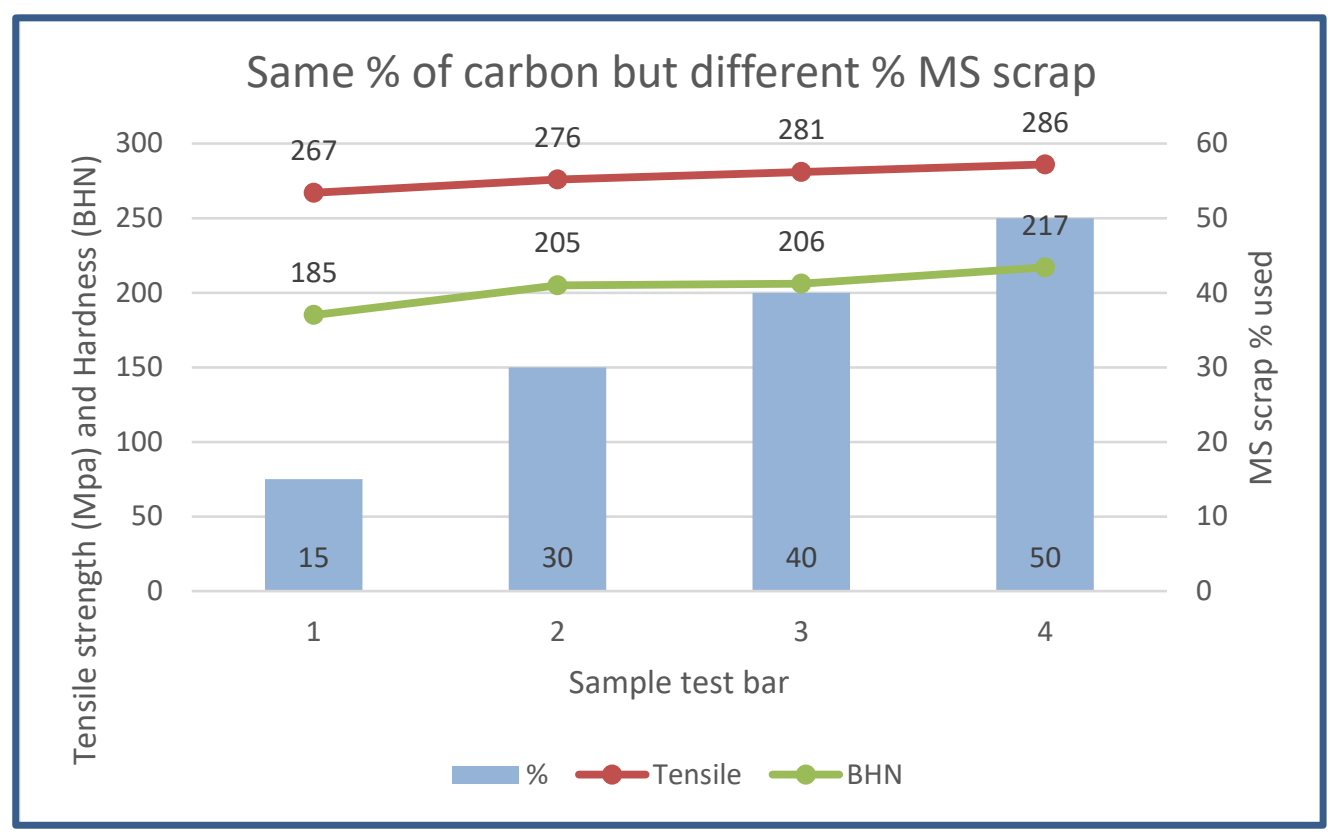

Figure 2.2 Same Carbon Content but Different MS Scrap \%

3) Tensile strength analysis against Different pouring temperature.

To study the effect of pouring temperature on the tensile strength of grey cast iron melt, test bars are poured at different pouring temperature for the same melt of grey cast iron. This is to study that is there any considerable phase change occur or not while pouring as well as at the time of solidification of melt material. The test bars are poured at temperature as low as possible (Below this temperature unable to pour test bar because it gets solidifies while pouring into the test bar mould). The test bars are poured with temperature difference of about $50{ }^{\circ} \mathrm{C}$ approximately.

Table 3.1 Test Bar at Different Pouring Temperature

\begin{tabular}{|c|c|c|}
\hline Sr. & $\begin{array}{c}\text { Temperature } \\
\left({ }^{\circ} \mathrm{C}\right)\end{array}$ & Tensile strength (Mpa) \\
\hline 1 & 1305 & 279.12 \\
\hline 2 & 1351 & 281.59 \\
\hline 3 & 1401 & 274.17 \\
\hline 4 & 1448 & 276.49 \\
\hline
\end{tabular}

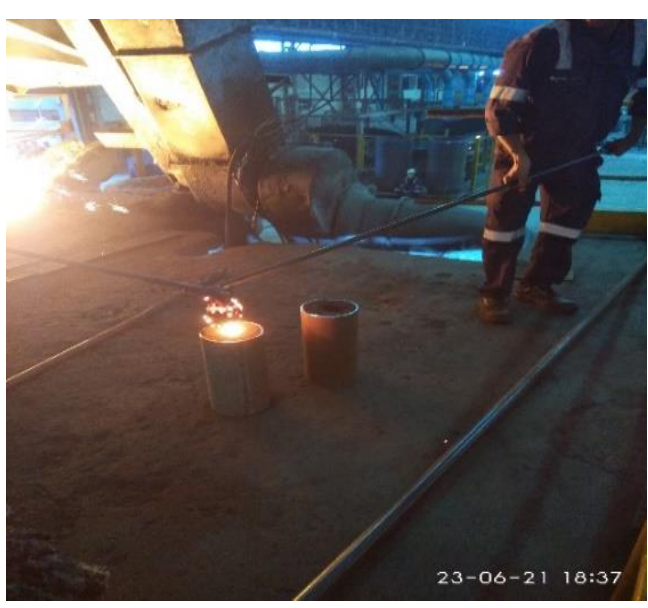

Picture 3.2 Test Bar Pouring 


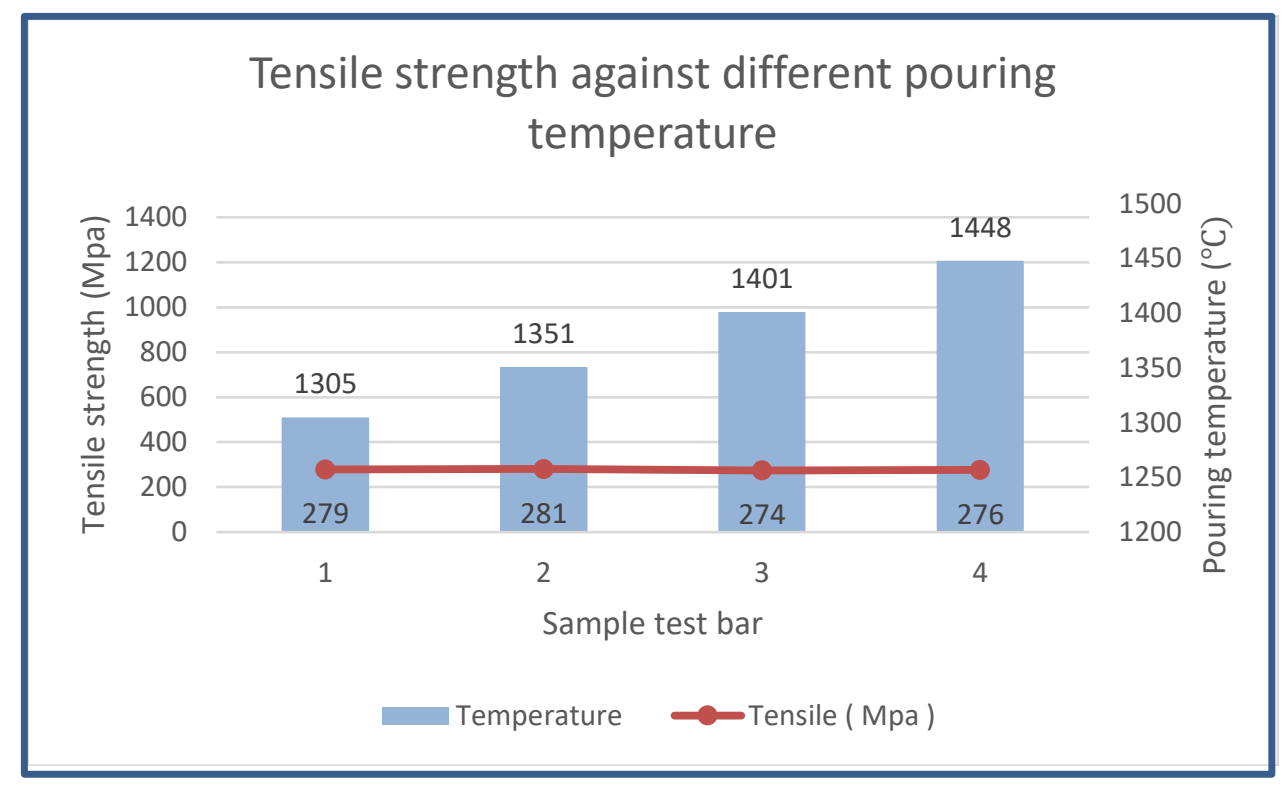

Figure 3.3 Tensile Strength Against Different Pouring Temperature

4) Tensile strength analysis against Different cooling time.

To study the behavior of tensile strength of grey cast iron for the different cooling time in sand mould, test bars are knock out at different period of time. The test bars are poured for same melt. Test are knock out at interval of 1 hour that is knock at 60, 120, 180, 240 min serially. While pouring the test bar care is taken that all other parameters are kept unchanged such as chemical compositions, charge mix, inoculation \%, cooling environment, inoculant base etc.

Table 4.1 Test bar knock out for different cooling time

\begin{tabular}{|c|c|c|}
\hline Sr. & Time & Tensile strength (Mpa) \\
\hline 1 & $60 \mathrm{~min}$ & 267.36 \\
\hline 2 & $120 \mathrm{~min}$ & 262.14 \\
\hline 3 & $180 \mathrm{~min}$ & 258.37 \\
\hline 4 & $240 \mathrm{~min}$ & 256.67 \\
\hline
\end{tabular}

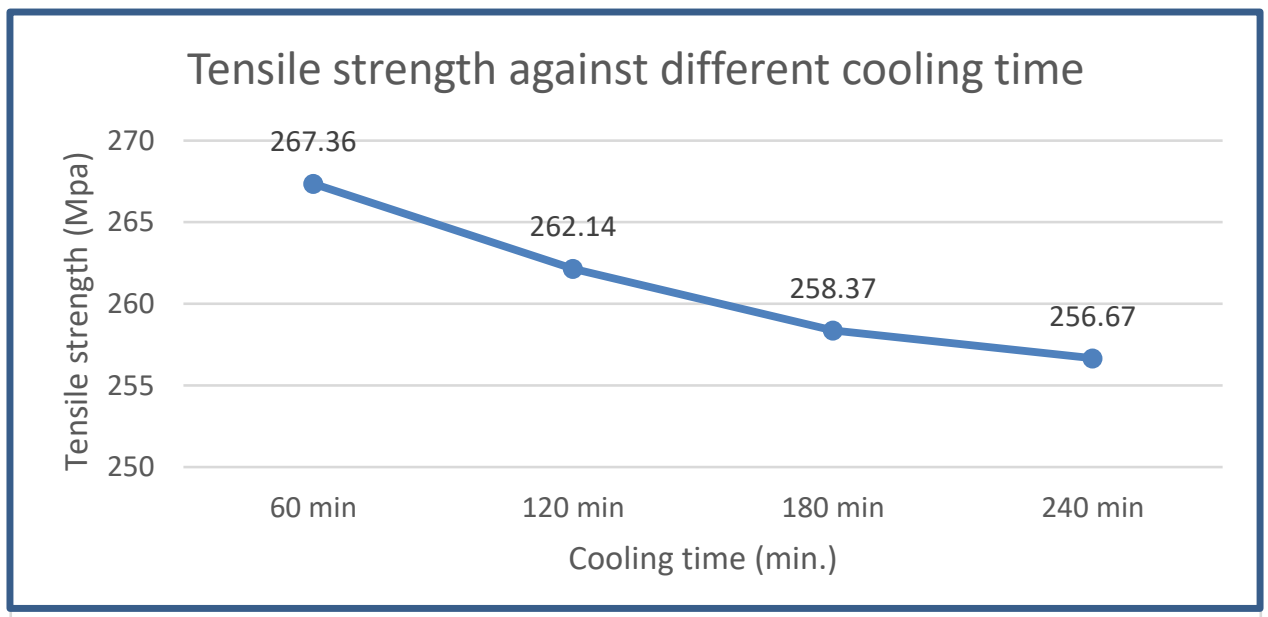

Figure 4.2 Test Bar Knock Out for Different Cooling Time 
5) Tensile strength analysis against different $\%$ of inoculant.

To study the behavior of tensile strength of grey cast iron with respect to different $\%$ of inoculation, test bars are poured with different $\%$ of inoculation for the same metal. Poured test bars are inoculated with same base of inoculant and specification are as given below.

Test bar poured for different \% of inoculant (Barium base)

Table 5.1

Table 5.2

\begin{tabular}{|c|c|c|}
\hline Sr. & \% Inoculation & $\begin{array}{c}\text { Tensile Strength } \\
\text { (Mpa) }\end{array}$ \\
\hline 1 & 0 & 246.63 \\
\hline 2 & 0.1 & 269.85 \\
\hline 3 & 0.2 & 268.53 \\
\hline 4 & 0.3 & 257.46 \\
\hline
\end{tabular}

\begin{tabular}{|c|c|c|}
\hline Sr. & \% Inoculation & $\begin{array}{c}\text { Tensile strength } \\
\text { (Mpa) }\end{array}$ \\
\hline 1 & 0 & 236.74 \\
\hline 2 & 0.15 & 269.11 \\
\hline 3 & 0.3 & 257.01 \\
\hline 4 & 0.45 & 254.79 \\
\hline
\end{tabular}

Chemical composition for poured test bar at different $\%$ of inoculant Table no. 5.1a

\begin{tabular}{|c|c|}
\hline Alloy & $\%$ \\
\hline Carbon & 3.25 \\
\hline Silicon & 1.84 \\
\hline Chromium & 0.21 \\
\hline Copper & 0.24 \\
\hline Manganese & 0.64 \\
\hline
\end{tabular}

\begin{tabular}{|c|c|}
\multicolumn{2}{|c}{ Table no. 5.2a } \\
\hline Alloy & $\%$ \\
\hline Carbon & 3.29 \\
\hline Silicon & 1.81 \\
\hline Chromium & 0.22 \\
\hline Copper & 0.24 \\
\hline Manganese & 0.64 \\
\hline
\end{tabular}

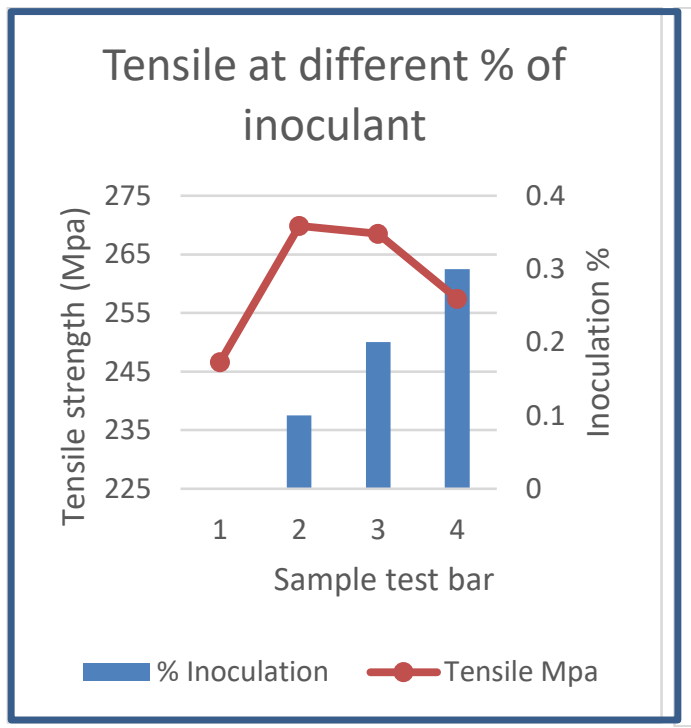

Figure 5.1b Different \% of Inoculant

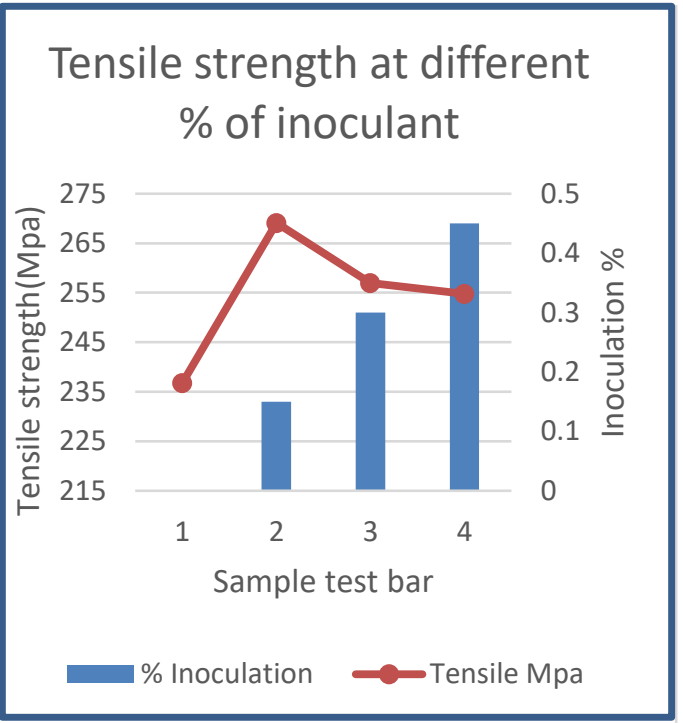

Figure 5.2b Different \% of Inoculant

6) Tensile strength analysis against different Inoculant base.

To study the effect on tensile strength of base of inoculant, test bars are poured for base Barium and base Strontium for the same melt of grey cast iron. This is because the chemical composition in the melt as well as composition in the inoculant affects the solidification of melt and corresponding mechanical properties of grey cast iron melt. The test bars are poured without changing the chemical composition of melt, charge mix, 
cooling condition.

Table 6.1 Test Bar for Different Base of Inoculant

\begin{tabular}{|c|c|c|c|}
\hline \multicolumn{4}{|c|}{ Tensile strength for different base } \\
\hline Sr. & Barium base $\%$ & Sr Base $\%$ & Tensile strength (Mpa) \\
\hline 1 & 0.1 & - & 281 \\
\hline 2 & - & 0.1 & 277 \\
\hline 3 & 0.2 & - & 275 \\
\hline 4 & - & 0.2 & 265 \\
\hline
\end{tabular}

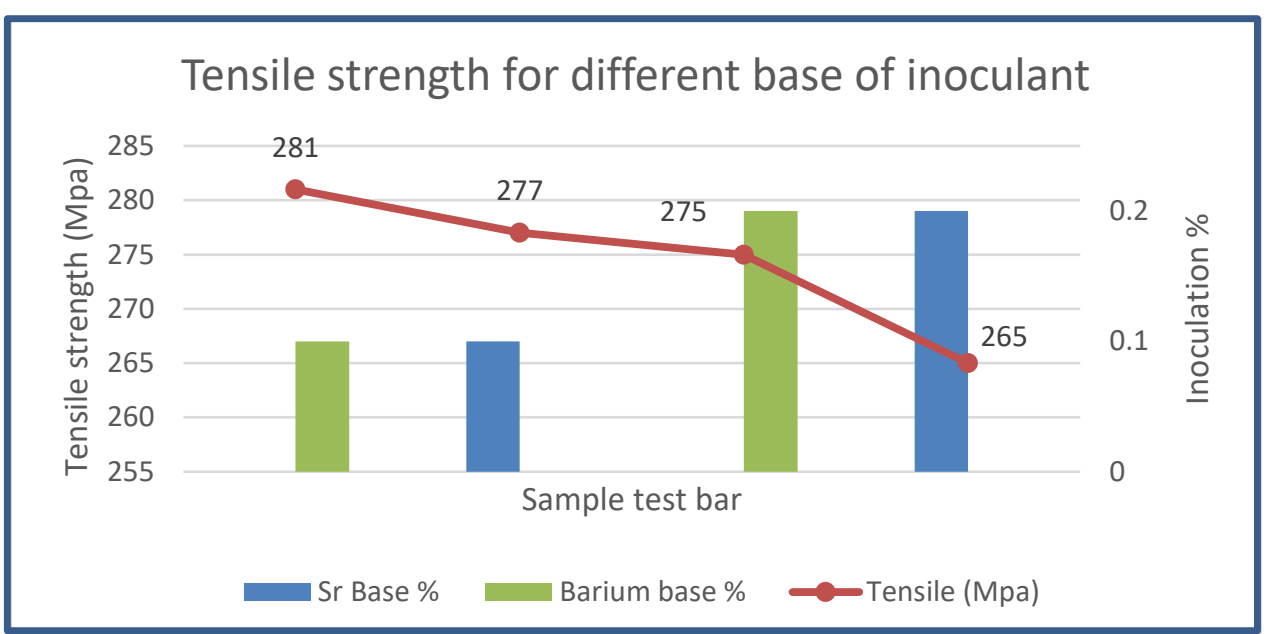

Figure 6.2 Tensile Strength for Different Base of Inoculant

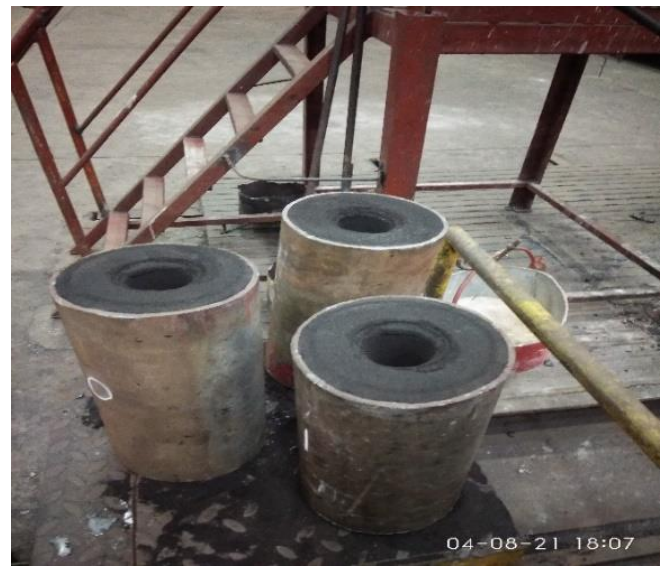

Picture 6.3 Test Bar Mould

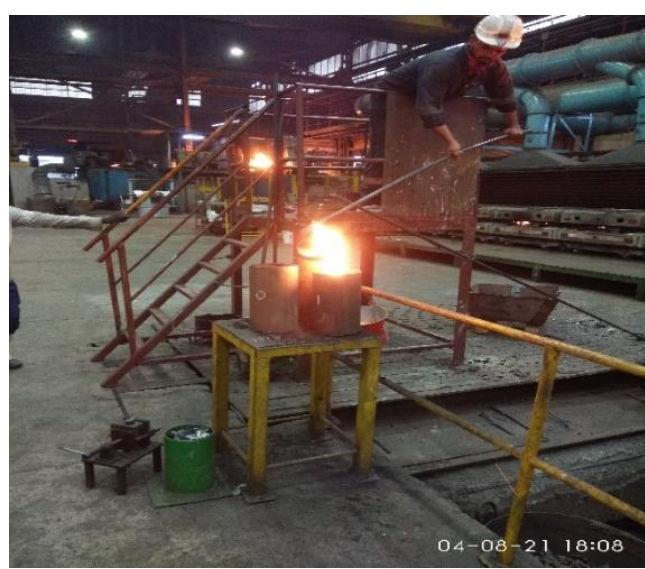

Picture 6.4 Test Bar Pouring

\section{Result:}

1) Effect of Carbon content in metal and its effect on tensile strength of metal

From the experiment carried out with varying carbon content in the grey cast iron keeping charge mix unchanged, it comes to know that the tensile strength goes on decreasing as carbon $\%$ goes on increases. The experiment is carried out for carbon content in the melt from $3.20 \%$ to $3.35 \%$, keeping other alloying elements unchanged. 
2) Effect of MS scrap \% used to produce cast iron and its effect on tensile strength of metal

Keeping carbon \% constant and varying the MS \% used in the charge shows the variation of tensile strength of grey cast iron. As \% of MS scrap used goes on increasing, the tensile strength increases as well.

3) Effect of pouring temperature on tensile strength of poured metal.

Test bars are poured at different pouring temperatures for same metal. Result of tensile strength shows that pouring test bar at different pouring temperature does not affect tensile strength considerably.

4) Effect of cooling time (knock out time) on tensile strength of metal

Poured test bar of same metal are allow to cool for different cooling time. The result shows that the tensile strength goes on decreasing as cooling time is increased.

5) Effect of different inoculation $\%$ on tensile strength of poured metal.

Pouring test bar of same metal for different \% of inoculant shows that uninoculated test bar carries lower tensile strength. Inoculated test bar carries higher tensile strength than uninoculated test bar. Beyond certain limit of \% of inoculant, tensile goes on decreasing.

6) Effect of different base inoculation on tensile strength of poured metal.

Test bars are poured with different base of inoculant and result shows that the Barium base inoculant gives better tensile strength than the Strontium base inoculant.

\section{Conclusion:}

From the experiments carried out there are following conclusions

1) As carbon $\%$ in the melt of grey cast iron increases, tensile strength goes decreases

2) Tensile strength of grey cast iron goes on increases with increase in $\%$ of MS scrap used in the charge keeping chemical composition unchanged of melt.

3) Pouring temperature of test bar does not affect tensile strength of grey cast iron considerably.

4) As cooling time for test bar of grey cast iron is increased, tensile strength of test bar goes on decreasing.

5) Uninoculated test bar carries lower tensile strength and tensile strength of test bar increases with addition of inoculant up to certain limit and goes on decreasing after exceeding the limit.

6) Barium base inoculant gives better tensile strength as compare to Strontium base inoculant.

\section{Acknowledgement}

We would like to express our sincere gratitude to Menon and Menon Ltd. for sponsoring our project and research paper and support for the same. Firstly, we would like to express our sincere gratitude to General Manager Rahul Patil sir, Development, Production and Quality department for their support, helpful information and advices, patience helped too much to complete this research paper.

We would also thankful of all faculties, coordinator, mentor from DKTE's Textile and Engineering Institute, Ichalkaranji for their valuable guidance and support. 


\section{References:}

1. V. Fourlakidis, L. V. Diaconu, b and A. Dioszegi (2010) "Effects of Carbon Content on the Ultimate Tensile Strength in Grey Cast Iron" Materials Science Forum Vol. 649 (2010) pp 511-516.

2. Hiren V. Mandalia, Vijaykumar R. chavda (2018) "Effect of Chemical Composition on Total Carbon Equivalent in Grey Iron Casting" International Research Journal of Engineering and Technology (IRJET) Volume: 05 Issue: 06.

3. Peter Futas, Alena Pribulova Gabriel Fedorko and Vieroslav Molnar (2017) "Influence of Steel Scrap in the Charge on the Properties of Grey Cast Iron" ISIJ 374 ISIJ International, Vol. 57 (2017), No. 2, pp. 374-379.

4. Attila Dioszegi, Vasilios Fourlakidis and Ingavar L Svensson "Microstructure and tensile properties on grey cast iron" Research report 04:1 ISSN 1404-0018, school of engineering, Jonkoping, University Sweden.

5. Prof.S.C.Borse, Y.E.Mangulkar (2014) "Review on Grey Cast Iron Inoculation" International Journal of Innovative Research in Science, Engineering and Technology, Volume 3, Special Issue 4, April 2014. 